\title{
AS IMPLICAÇÕES DA CAPACITAÇÃO NAS CRENÇAS DE AUTOEFICÁCIA DE GESTORES TÉCNIÇO- ADMINISTRATIVOS DE UMA INSTITUIÇÃO FEDERAL DE EDUCAÇÃO SUPERIOR
}

\author{
THE IMPLICATIONS OF TRAINING IN SELF-EFFICACY BELIEFS \\ OF TECHNICAL-ADMINISTRATIVE MANAGERS IN A FEDERAL \\ INSTITUTION OF HIGHER EDUCATION
}

Data de submissão: 03/01/2014 Aceite: 03/06/2015

Keliane de Oliveira Cavalcante ${ }^{1}$ Anielson Barbosa da Silva²

\section{RESUMO}

O artigo objetiva analisar as implicações da capacitação nas crenças de autoeficácia de gestores técnico-administrativos de uma Instituição Federal de Ensino Superior (IFES). A pesquisa é de natureza qualitativa e foi realizada com 12 gestores, por meio de entrevistas semiestruturadas. A análise dos discursos revelou percepções dos sujeitos sobre as implicações da capacitação nas crenças de autoeficácia e no desenvolvimento de competências. Os resultados da pesquisa revelam a necessidade da IFES incluir nos processos de capacitação, além da noção de competências, uma análise das crenças dos gestores sobre suas capacidades, por meio da exploração do construto autoeficácia como determinante no planejamento das ações de desenvolvimento gerencial. Sobre os vínculos entre o nível de autoeficácia e a capacitação dos gestores, conclui-se que os gestores pesquisados geram um impacto positivo em seu trabalho em função de suas crenças de autoeficácia, uma vez que as experiências vividas contribuíram para dar mais segurança na realização das atividades e os ajudaram a lidar com as situações difíceis e os processos de solução de problemas. Espera-se que o estudo auxilie na introdução da autoeficácia como um construto determinante na elaboração de programas de desenvolvimento gerencial.

Palavras-Chave: autoeficácia; capacitação; instituições federais de ensino superior; desenvolvimento de competências; servidores públicos.

\footnotetext{
1 Possui graduação e mestrado em Administração de Empresas, pela Universidade do Estado do Rio Grande do Norte. Atualmente é Administradora na Universidade Federal Rural do Semi-Árido - UFERSA. Mossoro. Rio Grande do Norte. Brasil. E-mail: kelianecavalcante@ hotmail.com

2 Possui graduação e mestrado em Administração pela Universidade Federal da Paraíba e doutorado em Engenharia de Produção pela Universidade Federal de Santa Catarina. João Pessoa. Paraíba. Brasil. E-mail: anielson@uol.com.br
} 


\begin{abstract}
The article aims to analyze the implications of training in self-efficacy beliefs of technical-administrative managers of a Federal institution of higher education (IFE). The research is qualitative in nature and was realized with 12 managers, using semi-structured interviews. The discourse analysis revealed perceptions of the subject on the implications of training in the beliefs of self-efficacy and in the development of competences. The survey results reveal the necessity of the IFE include in training processes, beyond the notion of competences, an analysis of managers' beliefs about their capabilities, through the exploration of self-efficacy construct as determinant in the planning of the actions of managerial development. About the links between the level of self-efficacy and managers training, it is concluded that the managers surveyed generate a positive impact in their work because on their self-efficacy beliefs, since the experiences contributed to give more security in carrying out the activities and helped them deal with the difficult situations and problem-solving processes. The study is expected to assist in the introduction of self-efficacy as a key construct in managerial development programmes.

Keywords: self-efficacy; training; federal institutions of higher education; development of competences; public servants.
\end{abstract}

\title{
1 INTRODUÇÃO
}

O sentido do trabalho na esfera pública sofreu modificações a partir de uma maior preocupação do Estado com a qualificação dos servidores, a necessidade de redefinição do papel do servidor, de sua profissionalização e da institucionalização de mecanismos legais que suscitam uma orientação mais estratégica para a gestão de pessoas, por meio do estabelecimento de políticas que orientem as ações dos gestores em prol do desenvolvimento dos servidores (FARIAS; GAETANI, 2002; PIRES ET AL., 2005).

As Instituições Federais de Ensino Superior (IFES) passaram por mudanças na área de gestão de pessoas, sobretudo, a partir da publicação da lei no 11.091/2005, que institucionalizou o Plano de Carreira dos Cargos dos Servidores Técnico-Administrativos em Educação (PCCTAE). Em 2006, o governo federal institucionalizou a Política Nacional de Desenvolvimento de Pessoal (PNDP), com o objetivo de delimitar parâmetros para balizar o processo de desenvolvimento dos servidores públicos federais, que também trouxe implicações para a gestão de pessoas no contexto das instituições públicas federais.

Tais dispositivos legais demandaram das IFES a necessidade de institucionalizar planos de desenvolvimento para seus servidores, além de programas de avaliação de desempenho e de dimensionamento de pessoal. Entretanto, várias IFES tiveram dificuldade de institucionalizar práticas de gestão de pessoas mais alinhadas com o plano de desenvolvimento institucional, o que trouxe dificuldades para tornar a legalidade uma realidade (OLIVEIRA; SILVA, 2011).

As IFES tiveram que institucionalizar políticas de gestão de pessoas voltadas para o desenvolvimento permanente do servidor, como preconizado pela PNDP, que recomenda a introdução de sistemas de gestão por competência, orientados para a capacitação e o desenvolvimento do servidor para o desempenho das suas funções, visando ao alcance dos objetivos da instituição.

Os gestores públicos são os responsáveis pela formulação e implantação de programas e ações e a qualificação dos gerentes passa a ser determinante para que as IFES gerenciem de forma adequada os seus recursos. Nesse processo, as ações de capacitação e desenvolvimento devem focalizar no desenvolvimento de competências gerenciais e também da autoeficácia gerencial, para que o servidor em cargo de gestão acredite em sua capacidade para realizar suas tarefas e alcançar bons níveis de desempenho. 
Percebe-se a importância de analisar os vínculos existentes entre os mecanismos da capacitação, as formas de aprendizagem e promoção do desenvolvimento de competências e de autoeficácia, uma vez que as pesquisas sobre autoeficácia revelam que não basta o individuo ser capaz, é preciso que o mesmo acredite na sua capacidade para obter sucesso nas tarefas que desempenha. (BANDURA, 1988; NAVARRO, 2003).

Associada a noção das competências, a autoeficácia pode ser entendida como uma crença ligada às convicções do indivíduo sobre as suas habilidades de mobilizar atributos ligados à dimensão cognitiva, motivacional e comportamental daqueles que estão envolvidos no processo de formação gerencial. Como ressalta Bandura (1977a) e Azzi e Polydoro (2006), não basta possuir as competências, pois é preciso acreditar que se pode desempenhá-las, o que mantem uma aderência à noção de competência proposta por Le Boterf (2003).

Mesmo que as crenças de autoeficácia sejam construídas no decorrer da vida, elas também podem ser desenvolvidas (MARTÍNEZ; SALANOVA, 2006). Além de variável preditora (BANDURA, 1977a; ABBAD; BORGES-ANDRADE, 2004; PANTOJA ET AL., 2005; MARTíNEZ; SALANOVA, 2006; MENESES; ABBAD, 2004, 2010; TAMAYO; ABBAD, 2006), a autoeficácia pode ser desenvolvida por meio da capacitação.

As crenças de autoeficácia no contexto da ação profissional atuam como um mecanismo importante diante das demandas do ambiente, sendo capazes de impulsionar o desempenho profissional, promover a adaptação às mudanças aos processos de capacitação dos indivíduos com relação à aquisição de novas competências e a transferência da aprendizagem para o trabaIho (MARTíNEZ; SALANOVA, 2006).

A autoeficácia é tida como variável significativa na condução da aprendizagem e no desempenho profissional (SALAS; CANNON-BOWERS, 2001). Esses autores enfatizam que as variáveis: motivação para aprender, auto-eficácia, aprendizagem e transferência da aprendizagem demandarão uma maior atenção dos pesquisadores nos próximos anos, devido à necessidade de estudos que expliquem suas relações com outros construtos. Abbad e Borges-Andrade (2004) discorrem sobre as evidências empíricas que variáveis individuais, a exemplo da motivação e autoeficácia, podem explicar resultados de aprendizagem e transferência de conhecimento.

Este artigo tem como objetivo analisar as implicações da capacitação nas crenças de autoeficácia de gestores técnico-administrativos de uma Instituição Federal de Ensino Superior. O estudo pode contribuir para ampliar a compreensão sobre os vínculos entre capacitação, autoeficácia e desenvolvimento de competências gerenciais no contexto das Instituições Federais de Educação Superior.

$\mathrm{O}$ artigo está estruturado em quatro partes além desta introdução. O referencial teórico discute a aprendizagem e sua relação com o desenvolvimento de competências gerenciais, a mudança comportamental no ambiente da ação profissional, além da autoeficácia e sua influência no comportamento humano. O percurso metodológico delimita a trajetória percorrida pelos pesquisadores na delimitação do tipo de pesquisa, do contexto, dos sujeitos, do instrumento de coleta de dados e dos procedimentos de análise dos dados. Em seguida, são apresentados os resultados da pesquisa, além das conclusões e recomendações para estudos futuros.

\section{REFERENCIAL TEÓRICO}

Esta seção apresenta a teoria de base para a análise do fenômeno que analisa as implicações da capacitação nas crenças de autoeficácia. Inicialmente, discute-se a aprendizagem e o desenvolvimento de competências gerenciais. Em seguida, apresenta-se a interação entre aprendizagem e mudança comportamental no ambiente da ação profissional. Por fim, analisa-se a influência da autoeficácia no comportamento humano. 


\subsection{Aprendizagem e desenvolvimento de competências}

Os vínculos entre aprendizagem e competências já estão bem delimitados na literatura. Silva e Godoi (2006) analisam a relação entre aprendizagem e competências a partir de uma lógica dialética e bidirecional. As competências, segundo Cheetham e Chivers (2005), categorizam as competências em quadro dimensões: cognitivas (relacionadas à compreensão de assuntos, objetos, ações, métodos, etc.); funcionais (que se referem à atuação do trabalho em si); comportamentais (relacionadas à personalidade do gestor, sendo requeridas no contexto da ação profissional); e, de valores e ética (voltadas à conduta adequada na função gerencial).

No Brasil, Pires et al. (2005) constataram que as atividades de desenvolvimento de competências podem auxiliar o planejamento das carreiras de Estado na Administração Pública Federal, sob a definição dos "CHAs", que são os conhecimentos, habilidades e atitudes necessários a cada classe ou padrão de uma carreira, mediante escalas de complexidade, a fim de promover a adequação dos aspectos cognitivos e comportamentais dos indivíduos à qualidade dos serviços públicos prestados.

A PNDP estabelece que o alcance de melhores resultados na esfera pública está vinculado à institucionalização da lógica das competências (BRASIL, 2006a), e coloca a capacitação como determinante nos processos de aprendizagem e para o desenvolvimento de competências dos gestores, que precisam atuar em contextos imprevisíveis e são demandados a prestar serviços de forma customizada para a sociedade (NICOLLAZI, 2012).

O Serviço de Gerenciamento de Pessoal dos Estados Unidos (Office of Personnel Management - OPM) identificou cinco qualidades imprescindíveis ao alto escalão do Serviço Público Federal (Senior Executive Service - SES), as quais propiciam uma boa definição das competências gerenciais necessárias a esses profissionais, no futuro, são elas: capacidade de liderar as mudanças, liderar pessoas, ser movido pelos resultados, ter um senso agudo dos negócios, e saber se comunicar e estabelecer coalizões (BACON, 1999).

Observa-se que a aprendizagem está diretamente relacionada à noção de competência. De modo simples, é como se a primeira variável fosse o processo necessário ao desenvolvimento da segunda. Silva e Godoi (2006, p. 63) destacam que "tomando a competência como objeto, o fenômeno da aprendizagem é que surge como o processo, o "como" necessário à competência".

Le Boterf (2003) discorre que o profissional sabe aprender não apenas em circuito simples, mas também em circuito duplo e fundamenta seu argumento em Argyris e Schön (1996). Vale reconhecer, então, o papel dos gerentes como os responsáveis por qualquer processo de mudança no serviço público, sendo indispensável desenvolver as competências necessárias à promoção das mudanças demandadas pelo contexto público na contemporaneidade.

O processo de aprendizagem gerencial pode ser balizado por ações de desenvolvimento formais ou informais (DUTRA, 2004). As experiências vivenciadas pelos gerentes em sua jornada de trabalho também podem contribuir para a sua aprendizagem, mas para que a aprendizagem ocorra, os gerentes precisam estar dispostos a refletir sobre suas experiências (DAUDELIN, 1996). Os programas de desenvolvimento gerencial devem considerar que o desenvolvimento de competências pode ocorrer na ação, mediado pelas experiências práticas (BACON, 1999). Para Raelin (2008), a aprendizagem em ação se tornou uma ferramenta indispensável no trabalho, não só para resolver problemas complexos, mas também para desenvolver líderes e equipes.

Mintzberg (2006) sugere algumas formas de desenvolvimento gerencial: movimentação, mentoria, monitoramento; buffet do desenvolvimento (entretenimento, ensino, treinamento e aprendizagem; customização, programas de liderança, programas de escolas de negócios, novos programas); aprender fazendo (estilo Revans; MiL - Management in Lund; O Work-Out na 
General Eletric) e; academias corporativas. Todavia, é importante enfatizar que o desenvolvimento de competências profissionais, focadas na mudança individual, pode não alcançar os efeitos esperados se o contexto e o ambiente organizacional não favorecerem a adoção desse novo olhar sobre a gestão de pessoas (PIRES et al., 2005).

Entende-se que aprendizagem implica mudança comportamental que pode ser expressa no contexto do trabalho. Para tanto, faz-se necessário caracterizar os vínculos entre a aprendizagem e a mudança comportamental no ambiente da ação profissional.

\subsection{Aprendizagem e mudança comportamental no ambiente da ação profissional}

A aquisição de uma nova competência revela que o indivíduo aprendeu algo novo, por ter mudado um modo de agir. Isso remonta ao enfoque cognitivista, mostrando que os assuntos aprendidos pelas pessoas (conhecimentos, habilidades e atitudes) são como elementos distintivos da sua competência, sob a apresentação de um novo comportamento (Brandão, 2008).

Abbad e Borges-Andrade (2004:238) explicam que "a aprendizagem é um processo psicológico que ocorre no nível do indivíduo". Merriam, Caffarela e Baumgartner (2007) propõem cinco principais perspectivas teóricas norteadoras da aprendizagem: a behaviorista, a cognitiva, a humanista, a social e a transformadora. Na perspectiva behaviorista, a aprendizagem é traduzida pela mudança comportamental, determinada por elementos do ambiente e não do aprendiz individualmente. Já a cognitiva entende que o ser humano é um agente ativo no processo de aprendizagem, interpretando sensações e atribuindo significados aos eventos que afetam a sua consciência. Para a perspectiva humanista, a aprendizagem decorre da motivação do indivíduo e abrange responsabilidades. Não obstante, a social postula que a aprendizagem resulta da observação de outras pessoas em determinados contextos. Por fim, a perspectiva transformadora é conseqüência da transformação de um conhecimento existente numa nova abordagem, ocasionando a emancipação do aprendiz.

Para Fleury e Fleury (2001, p. 191) a "aprendizagem pode ser assim pensada como um processo de mudança, provocado por estímulos diversos, mediado por emoções, que podem vir ou não a manifestar-se em mudança no comportamento da pessoa". Já Abbad e Borges-Andrade (2004) entendem que de um modo geral a aprendizagem está relacionada às mudanças comportamentais do indivíduo resultantes não apenas das experiências, mas também de sua interação com o contexto.

Como se vê, a mudança comportamental como resultado da aprendizagem, pode ser analisada a partir de várias abordagens e perspectivas teóricas. As discussões sobre aprendizagem individual a partir de programas formais de capacitação nas organizações têm uma base forte na perspectiva cognitivista, destacando, porém, as mudanças comportamentais observáveis.

Do mesmo modo em que a abordagem da aprendizagem individual reconhece que aprender implica mudar de comportamento, as vertentes que estudam a aprendizagem de gerentes compreendem que ela também ocorre no ambiente laboral por meio da relação com experiência, o contexto social e a reflexão. De caráter multidimensional, ela envolve tanto a dimensão técnica associada ao conhecimento, quanto o entendimento do contexto da ação profissional, contribuindo para o desenvolvimento de habilidades, impulsionando o processo de mudança sob o ponto de vista de significado, expandindo as perspectivas de comportamentos dos indivíduos e auxiliando-os em seu autodesenvolvimento (SILVA, 2008, 2009).

A mudança no comportamento como resultado da aprendizagem e do desenvolvimento de competências também pode ser analisada a partir do construto autoeficácia, uma vez que estudos têm demonstrado que essa variável é preditora da aprendizagem, bem como requisito imprescindível ao desempenho competente. 


\subsection{A autoeficácia e suas influências no comportamento humano}

A mudança comportamental do indivíduo está sujeita as expectativas sobre o resultado e a eficácia pessoal. As expectativas quanto ao resultado se baseiam no entendimento que um comportamento particular conduz a uma consequência específica. São crenças sobre a consequência de um ato. Já as expectativas de autoeficácia referem-se ao controle pessoal das ações, à competência do indivíduo para realizar um comportamento característico desejado (BANDURA, 1989).

A autoeficácia é uma crença relativa às convicções do indivíduo acerca das suas habilidades de mobilizar suas facilidades cognitivas, motivacionais e de comportamento, imprescindíveis a realização de uma tarefa específica em determinado momento e em dado contexto. A autoeficácia percebida se refere ao julgamento de poder realizar algo considerando as suas habilidades sob uma variedade de circunstâncias (AZZI; POLYDORO, 2006). As crenças de autoeficácia representam uma estrutura cognitiva que intercede no conhecimento e na ação, determinando, junto com outras variáveis, o sucesso das próprias ações. Percebe-se, então, que não basta possuir competências, também é preciso acreditar que as possui (BANDURA, 1988; NAVARRO, 2003).

As crenças de autoeficácia são resultantes de quatro fontes diferentes: experiência de domínio (observação direta), experiência vicária, persuasão verbal e estado fisiológico (BANDURA, 1977a, 1999). Sobre isso, a dimensão vista como a mais importante, por estar relacionada à capacidade do sujeito de obter sucesso em situações difíceis, é a experiência de domínio. Pelo seu caráter pessoal, este fator é essencial ao conceito de autoeficácia (BANDURA, 1977a, 1999; PAJARES; OLAZ, 2008).

As experiências de domínio estão voltadas às situações nas quais o indivíduo, diante de uma situação difícil, consegue obter sucesso, sendo-lhe útil e servindo-lhe ao encorajamento quando houver a ocorrência de uma situação similar. Elas são a maior influência à autoeficácia (BANDURA, 1977a, 1982,1986). As experiências vicárias envolvem as comparações sociais que as pessoas fazem entre si mesmas, as suas próprias capacidades e as capacidades dos outros. Ela é especialmente relevante quando os indivíduos não têm um grande conhecimento acerca das suas próprias habilidades ou têm pouca experiência na tarefa. (BANDURA, 1982, 1986; MARTíNEZ; SALANOVA, 2006). A persuasão verbal é formada através do reforço social, da crítica positiva, do louvor e palavras de encorajamento proferidas por pessoas confiáveis sobre as capacidades de um indivíduo, em complementaridade a informação diretamente obtida (BANDURA, 1977a, 1982). Os estados fisiológicos indicam que a forma como os indivíduos interpretam o seu estado físico, impacta em sua autoeficácia. Assim, ao julgar as suas habilidades, as pessoas também respondem de certo modo às informações fornecidas pelos seus estados físicos e emocionais (BANDURA, 1982).

O processamento cognitivo da eficácia diz respeito aos fatores que as pessoas aprenderam a empregar como indicadores de autoeficácia e as regras de inferência usadas para integrar informações das suas diferentes fontes (BANDURA, 1982). Desse modo, observa-se a importância exercida pela cognição na formação da autoeficácia. No entanto, cabe ressaltar que as crenças formadas por esse processo não são estáveis. Bandura (1977b) mostra que a autoeficácia é mutável, variando entre outros aspectos, mediante o contexto e a situação, ao longo do tempo.

Existe um grande interesse de pesquisadores, principalmente estrangeiros, em aprofundar a associação entre a autoeficácia e os resultados de treinamento. Alguns pesquisadores entendem que as aptidões não sofrem influência das ações de treinamento, desenvolvimento e educação (TD\&E). Já outros, percebem que o nível de autoeficácia, alguns traços de personalidade e algumas medidas de inteligência podem ser mudados por meio dessas ações (ABBAD; BORGES-ANDRADE, 2004). 
Abbad e Borges-Andrade (2004) apontam que a autoeficácia tem um papel importante com relação à eficácia de TD\&E. Pantoja et al. (2005) citam dados de pesquisas analisadas evidenciando que as crenças de autoeficácia exercem influência positiva sobre a aprendizagem e desempenho dos treinandos, entre elas, Salas e Cannon-Bowers (2001). Por sinal, a autoeficácia ocupa posição de destaque no referencial teórico abordado por esses últimos autores.

As implicações das competências no desempenho dependem de crenças pessoais. É o esforço, a persistência e a perseverança que, em conjunto com as competências, influenciam o desempenho das pessoas (JAINA; TYSON, 2004). Assim, a autoeficácia propõe que os indivíduos alcançarão mais facilmente bons resultados em programas de TD\&E quando eles acreditam que são capazes de aprender seus conteúdos (BANDURA, 1977a; ABBAD; BORGES-ANDRADE, 2004).

As crenças de autoeficácia são construídas no decorrer da vida, e mesmo apresentando alguma estabilidade, nota-se que é possível desenvolvê-las. Assim, torna-se relevante promover mecanismos capazes de gerar crenças de eficácia em novos contextos ou domínios já experenciados (MARTíNEZ; SALANOVA, 2006). Essas considerações indicam que há evidências da existência de uma relação de reciprocidade entre autoeficácia e capacitação. A autoeficácia tanto auxilia no aproveitamento das ações de capacitação quanto pode ser desenvolvida e/ou ampliada por meio dessas.

Martínez e Salanova (2006) sugerem que, no campo da Gestão de Recursos Humanos, pode haver duas linhas de intervenção no desenvolvimento de autoeficácia dos colaboradores. A primeira, destinada ao incentivo da construção de reais juízos de autoeficácia, mediante o planejamento de objetivos específicos e estratégias dirigidas à sua consecução e critérios claros na hora de avaliar a execução e desempenho. A segunda, diretamente relacionada às quatro fontes de autoeficácia, capazes de gerar e desenvolver as crenças de eficácia tanto no nível pessoal quanto no grupal.

A constatação de que há uma interdependência dos construtos abordados pode contribuir para entender a contribuição da capacitação no desenvolvimento da autoeficácia, uma vez que ela comporta diversas formas de aprendizagem e tem sido buscada em função do desenvolvimento de competências, que é um conceito muito difundido no contexto deste estudo, além de ser um requisito necessário aos gestores técnico-administrativos. Entretanto, possuir competências, por si só, não é suficiente para o alcance dos objetivos desejados, uma vez que, como foi abordado nesta literatura, não basta ser competente, é preciso acreditar na sua capacidade.

\section{METODOLOGIA}

$\mathrm{Na}$ intenção de alcançar o objetivo traçado, utilizou-se a abordagem qualitativa (GODOY, 1995; MERRIAM, 2009), de natureza exploratória, uma vez que se pretende analisar as implicações da capacitação nas crenças de autoeficácia de servidores públicos que exercem uma função gerencial, permitindo entender como os sujeitos pesquisados atribuem significados as suas experiências que elas têm do mundo, indo ao encontro do objetivo geral da pesquisa.

O contexto da pesquisa é uma Instituição Federal de Ensino Superior localizada no nordeste brasileiro, que possui em seu quadro, mais de 5000 mil servidores, tendo sido uma das primeiras a implantar o plano de desenvolvimento dos integrantes da carreira dos servidores técnico-administrativos em educação. Os sujeitos da pesquisa foram os servidores técnico-administrativos ocupantes de função de gerencial, lotados em unidades inseridas no ambiente organizacional administrativo, que já tivessem participado de alguma ação de capacitação oferecida pela Unidade de Desenvolvimento de Recursos Humanos.

Participaram da pesquisa, doze gestores de diferentes unidades organizacionais, inseridas no ambiente mencionado, escolhidos por acessibilidade. Desses, sete são homens e cinco mulhe- 
res. A idade dos gestores variou entre 25 a 57 anos. Quanto a escolaridade, apenas dois possuem apenas o ensino médio, três são graduados, seis são especialistas e um possui o título de doutor. Metade dos entrevistados ocupa cargos de nível superior, a outra metade, ocupa cargos de nível intermediário. Com relação ao tempo de serviço no cargo, cinco o ocupam até dez anos e sete o ocupam a mais de vinte anos. As funções ocupadas por esses gestores também são variadas, temse chefes de seção, diretores de departamento, diretores de divisão e assessores técnicos. Sobre o tempo de serviço na função, três a exercem a menos de um ano, três a pouco mais de um ano, um a exerce há seis anos, um a exerce há dez anos, e quatro a exercem a mais de 15 anos.

A fim de não identificar os gestores, eles foram denominados na pesquisa como G1, G2, G3, ..., G12. Buscou-se verificar junto aos gestores técnico-administrativos que se dispuseram a participar das entrevistas, se existem implicações da capacitação com relação as suas crenças de autoeficácia no contexto da ação profissional.

O instrumento de coleta de dados utilizado para essa pesquisa foi um roteiro de entrevis$t a$, dividido em duas partes. A primeira abrange questões do perfil sócio profissional dos entrevistados, e a segunda parte apresenta 32 questões que foram elaboradas a partir dos autores analisados no referencial teórico sobre três dimensões: autoeficácia e comportamento na ação profissional, capacitação e desenvolvimento de competências e capacitação e desenvolvimento de autoeficácia.

A entrevista qualitativa foi utilizada com o objetivo de possibilitar uma compreensão mais ampla sobre as crenças, atitudes, valores e motivações acerca dos comportamentos das pessoas em contextos sociais específicos (GASKELL, 2008). Todas as entrevistas foram gravadas e transcritas literalmente, gerando protocolos, que foram analisados a fim de encontrar uma estrutura para o fenômeno. A duração de cada entrevista variou de 25 a 70 minutos.

A análise das implicações da capacitação de gestores técnico-administrativos de uma universidade federal nas suas crenças de autoeficácia instiga uma reflexão sobre os significados relacionados a essas variáveis. Assim, o método utilizado para compreender os significados do material coletado foi baseado na análise de discurso, que é um método que possibilita a compreensão de uma realidade manifestada por meio de discursos de indivíduos (CARRIERI ET AL., 2006).

A codificação foi feita com base em Silva (2005). Assim, como a pesquisa foi realizada com gestores, utilizou-se o código "GN.n", sendo que "G" refere-se ao gestor, "N", a sequência de entrevistados, e " $\mathrm{n}$ ", o número que representa o discurso extraído do protocolo de entrevistas. A partir das leituras e releituras dos protocolos, foi estabelecida a ordem dos discursos (SILVA, 2005).

O processo de análise do discurso seguiu as recomendações proposta por Gill (2008) e envolvendo duas fases: a procura por um padrão de dados e a identificação de funções de características específicas do discurso. A busca de padrões foi realizada a partir de uma leitura cética dos protocolos de entrevistas que auxiliou na codificação dos discursos dos entrevistados para avaliar as similaridades e variabilidades. Esse processo ajudou a delimitar as categorias de análise e possibilitou a identificação dos discursos mais significativos e que contribuíram para a compreensão do fenômeno das implicações das crenças de autoeficácia na capacitação dos gerentes da IFE investigada. A segunda fase da análise do discurso envolveu a identificação de funções e características específicas do discurso. Esta fase envolve o processo de análise interpretativa dos discursos e tem como objetivo revelar os significados manifestos e latentes nos relatos dos entrevistados. Essa etapa possibilitou o estabelecimento de uma estrutura de referência para entender o fenômeno. A próxima seção apresenta a análise dos significados dos discursos de forma compreensiva interpretativa. 


\section{ANÁLISE DOS RESULTADOS}

Os resultados da pesquisa sugerem a existência de uma relação recíproca entre autoeficácia e capacitação, uma vez que a capacitação pode potencializar ou desenvolver a autoeficácia, que pode levar os gerentes a tornar a capacitação em ações mais efetivas.

Os gestores revelaram que as ações de capacitação empreendidas pela organização contribuíram para a elevação dos seus níveis de autoeficácia e resultaram em um processo de aprendizagem e desenvolvimento de competências, mediados pelo ambiente institucional, como ilustra a figura 1.

Figura 1 - Implicações relacionadas à autoeficácia e à capacitação.

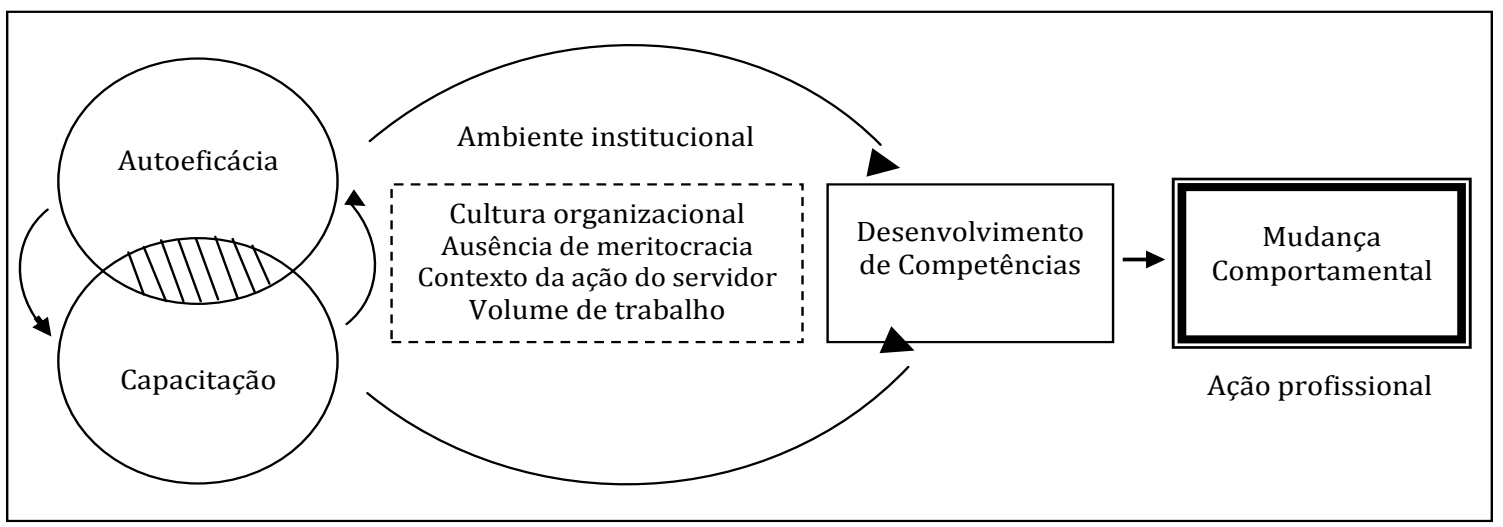

Fonte: Autores.

A figura indica que a autoeficácia tanto promove o melhor aproveitamento da capacitação quanto pode ser desenvolvida por ela. Todavia, devem ser observados os fatores limitantes existentes no ambiente institucional que podem influenciar os resultados dessas ações (cultura organizacional, ausência da meritocracia, contexto da ação do servidor, volume de trabalho).

Tais fatores podem contribuir para os bons resultados da capacitação, desde que sejam instituídos pela organização estudada, processos de avaliação e de reconhecimento do saber adquirido a partir da capacitação. Essa interação entre capacitação e autoeficácia contribui para o desenvolvimento de competências e mudança no comportamento dos gestores em sua ação profissional, o que pode fortalecer as suas crenças de autoeficácia.

\subsection{A capacitação e o desenvolvimento de competências}

Os resultados da pesquisa revelaram que as ações de capacitação contribuem para o desenvolvimento de competências, principalmente técnicas, e algumas comportamentais. Contudo, são necessárias adequações a fim de se buscar o atendimento da demanda de formação gerencial. Percebe-se a existência de vínculos entre competências e autoeficácia e que a capacitação potencializa o desenvolvimento de competências comportamentais.

A maior parte dos gestores assume a função de chefia por meio de uma indicação formal, e aprendem a serem gerentes, na prática: “(...) se você não teve experiência no seu curso de formação, como gestor, você só vai ter a experiência na prática" [GIII.10]. Alguns gerentes até entendem que esse é o curso normal para a atuação gerencial, desconsiderando outras opções à sua formação. Isso demonstra um curso inverso, e até contraditório, uma vez que eles reconhecem a importância da capacitação contínua e permanente. 
Assim, as experiências de domínio são fontes ricas de aprendizado, mas existe a necessidade de utilizar fontes, como a educação formal e a capacitação gerencial, a fim de promover melhores resultados para esses gestores. $O$ processo de aprendizagem também é mediado pelo contexto e pela experiência vivida, ocorrendo na ação, no cotidiano e especialmente nas trocas sociais. Os gerentes aprendem por meio das experiências vivenciadas (SILVA, 2009). Outro significado que emergiu da análise dos dados foi a motivação para capacitação a partir do resultado financeiro, a denominada "progressão por capacitação", pois como afirmou um dos entrevistados "aumentar o meu conhecimento, além das progressões e incentivos... não é só aumentar ou não o meu grau de conhecimento" [GII.12].

Um estudo realizado em outra IFES buscou avaliar a contribuição do PCCTAE para a capacitação e o desenvolvimento de competências gerenciais. Os resultados encontrados revelaram que, embora a capacitação institucional tenha sido elaborada com base no PCCTAE e na PNDP, as competências são mal entendidas por todos os gestores e a aprendizagem tem decorrido essencialmente da prática gerencial. Outra evidência é que a participação desses gestores em programas de capacitação está condicionada à motivação financeira. Portanto, eles entendem que tal capacitação deve ser aprimorada em muitos aspectos para contemplar as demandas vividas pela situação prática (CAVALCANTE; OLIVEIRA, 2011).

No contexto das IFES, deve-se fazer uma reflexão sobre a motivação para a capacitação, pois emergem valores que vinculam mais a capacitação à remuneração, transformando o objetivo da capacitação em uma questão econômica e relevando a importância da aprendizagem e do desenvolvimento de competências gerenciais como uma via para a modernização e a efetividade da gestão pública.

Os gestores técnico-administrativos são agentes de transformação e, considerando a sua relevância para a gestão pública, a demanda específica de capacitação nas IFES deve ser uma prioridade estratégica para o desenvolvimento institucional. Por outro lado, a função gerencial exige muito esforço e dedicação dos gestores, que demonstram dificuldade em conciliar a sua prática com os eventos de capacitação: O problema é que eu não estou conseguindo tempo para participar, mas vontade não me falta" [GXII.7].

A institucionalização de um programa de capacitação para os níveis gerenciais auxiliou no desenvolvimento de algumas competências, em especial as técnicas e comportamentais. Das seis competências comportamentais definidas pela Instituição estudada, pôde-se perceber que a maioria delas já era mobilizada pelos gerentes em sua ação profissional.

As competências comportamentais remetem a características que tornam as pessoas singulares e que são percebidas na ação gerencial, durante a interação com os servidores. Para Cheetham e Chivers (2005), a "competência pessoal ou comportamental" se refere à capacidade para adotar comportamentos apropriados observáveis em situações relacionadas ao trabalho.

De acordo com a percepção dos gestores pesquisados, apesar de o programa não estar adequado ao atendimento das demandas de capacitação gerencial, as ações cursadas por esses gestores proporcionaram mudança comportamental:

(...) a especialização me trouxe o diferencial "saber". Então, eu já penso hoje em gestão do conhecimento, gestão da qualidade de vida, abri os olhos para estudar cultura organizacional... Isso acaba influenciando a minha visão, e consequentemente, meu comportamento [GI.14].

... aumenta o nível de conhecimento de um modo geral, e você melhora o nível de qualidade na execução das atribuições. Hoje eu passei a dar um foco maior no controle das minhas atribuições. A minha capacitação, ela só me fez crescer como ser humano [GII.16]. 
Mudou assim, no sentido de você achar... tudo o que você faz, até mesmo um livro que você lê, te dá condições de ampliar o seu universo. Então para mim, ampliou mais meu universo [GVI.14].

Esses sujeitos entendem que conseguiram alcançar os resultados desejados, com relação aos cursos frequentados. Por outro lado, a mudança comportamental observada e o resultado da capacitação, de um modo geral, precisam estar mais relacionados à postura requerida ao papel do gerente. Por vezes, percebeu-se que os resultados alcançados se referiam à progressão por capacitação e ampliação de competências comportamentais.

Ficou nítida a necessidade de um planejamento mais específico, voltado à formação de um gestor público: "A gente tentou aprender no cargo, pela competência no trabalho. Então, você assume a função e depois que você vai desenvolver essa habilidade de trabalhar como gestor" [GVIII.13]. Alguns gestores acham normal a existência de uma lacuna de competências, e apontam que essa é uma dificuldade evidenciada por muitas IFES. Todavia, entende-se que o desenvolvimento de competências é fundamental a todos os níveis, promovendo o alcance dos objetivos organizacionais.

Nicolazzi (2012) conclui em sua pesquisa que os gestores acreditam na implantação de um modelo de gestão por competência nas organizações, uma vez que promove a sua capacitação e o seu alinhamento ao contexto profissional. Desse modo, faz-se necessário que essas instituições, considerando o seu aparato legal, promovam programas de capacitação balizados por trilhas de aprendizagem, que incluam linhas de desenvolvimento voltadas à gestão.

Os Planos de Desenvolvimento Institucional e de Desenvolvimento dos Integrantes da Carreira dos Técnico-administrativos da Universidade pesquisada indicam um alinhamento entre as práticas de gestão de pessoas e a estratégia organizacional. Mesmo assim, a IFE enfrenta dificuldades para promover a difusão de um sistema de gestão por competências e tal dificuldade, na maioria das IFES, envolve a compreensão limitada dos gestores sobre a noção das competências e que são determinantes na implantação de qualquer mudança institucional (CAVALCANTE; OLIVEIRA, 2011; OLIVEIRA; SILVA; CAVALCANTE, 2011).

A disseminação de programas de capacitação nas IFES pode contribuir para o desenvolvimento das crenças de autoeficácia, como revelam os resultados da próxima seção.

\subsection{Capacitação e desenvolvimento de autoeficácia}

Os resultados obtidos nesta dimensão sugerem que a capacitação pode contribuir para elevação dos níveis de autoeficácia (AE) dos gestores, muito embora os servidores pesquisados não tenham percebido uma associação direta.

A análise das entrevistas levou a identificação de significados que apontam, em especial, dois motivos para a elevação dos níveis de autoeficácia: primeiro, porque alguns entendem que já possuíam um nível elevado de $A E$, independente da capacitação; segundo, porque a metodologia das capacitações não incorpora de forma incisiva esse construto, mas foi percebido de forma clara, a partir da segurança advinda da aprendizagem de conteúdos, de trocas de experiências (em algumas situações) e da persuasão social exercida por alguns instrutores.

Ao compreender a autoeficácia como um atributo importante para o desempenho gerencial, os programas de desenvolvimento gerencial podem incorporar metodologias de aprendizagem que aproveitem o contexto social e as experiências profissionais dos gestores, a exemplo da aprendizagem em ação.

$O$ estudo realizado com os gerentes da IFE buscou entender como foi o processo de designação desses gestores para a sua função atual, os motivos que contribuíram para indicação desses servidores para exercer uma função gerencial, e ainda, se ocorreu alguma ação formal de capacitação para prepará-los para a função. 
Constatou-se que a mobilização dos gestores para a atuação gerencial está relacionada às crenças que envolvem a capacidade de realizar, que implica nível de autoeficácia elevado. Assim como em outras organizações públicas, os gestores da instituição pesquisada revelam que há motivos, além da competência, que levam as pessoas a se tornem gestores, indo de encontro ao que preconiza a legislação, especialmente, no âmbito das IFES. Tal constatação está ligada a aspectos arraigados na cultura organizacional do serviço público. Ressalta-se que alguns sujeitos foram preparados por colegas gestores ou mesmo por seus antecessores, os quais foram denominados de mentores.

Os gestores indicaram que o levantamento das necessidades de capacitação deve ser feito de forma mais eficaz, buscando abordar as necessidades observadas na prática das unidades:

(...) que esses cursos sejam mais direcionados para a parte de melhoria no ambiente de trabalho, da qualidade, abordando as necessidades dos servidores no trabalho, tentando suprir lacunas [GII.25].

\section{(...) fizessem uns cursos mais voltados, especificamente para área de gestão [GIX.14].}

Isso sugere a realização de um trabalho com os gestores, em parceria com a Unidade de Desenvolvimento de Gestão de Pessoas, institucionalizarem mecanismos formais de formação para aperfeiçoar o processo de capacitação gerencial.

Os entrevistados demonstraram entendimento sobre o papel da autoeficácia para a função. Em especial, apontaram que os cursos de capacitação precisam incluir uma abordagem mais atualizada e efetiva, que aproveite o papel do contexto da ação profissional, da experiência, com foco na aprendizagem em ação, favorecendo assim, a melhoria dos desempenhos observáveis na função gerencial. Para Salas e Cannon-Bowers (2001), a autoeficácia é uma variável expressiva na condução da aprendizagem e no desempenho profissional. Não obstante, Abbad e Borges-Andrade (2004) abordam sobre a existência de evidências empíricas de que variáveis de autoeficácia podem explicar resultados de aprendizagem e transferência.

Os resultados sugerem que a capacitação da forma como vem sendo implementada na IFES estudada vem contribuindo para o desenvolvimento de competências básicas, e pouco tem abordado o desenvolvimento gerencial e o reforço dos gestores na sua crença sobre a capacidade de gerenciar, ou seja, o desempenho das suas atividades:

O curso não. Acho que nenhum curso que eu tive oportunidade de participar ou de ver na lista, é voltado para trabalhar isso... e é muito importante, porque depois que eu cheguei, eu tive a oportunidade de ver, vivenciei situações, não comigo, mas com outros servidores, de estresse total, e acho que realmente, tem pessoas que não aguentam tanta pressão. No programa do DDRH, voltado pra esse gerenciamento pessoal mesmo, nunca vi não [GVII.17].

Os resultados do estudo possibilitaram o estabelecimento de alguns questionamentos: até que ponto os incentivos financeiros tem sido entraves à otimização dos resultados da capacitação das IFES? Será que a capacitação não está sendo planejada com vistas apenas a um cumprimento legal de oferta de cursos e oportunização de incentivos financeiros? Por que é tão difícil mudar a cultura organizacional das IFES? Será que essa dificuldade não está diretamente relacionada à falta de capacitação gerencial e aos fatores considerados para a designação das funções gerenciais?

Este estudo sinaliza alguns caminhos para promover ações de desenvolvimento gerencial visando legitimar o papel da meritocracia, da qualificação técnica e de crenças de autoeficácia que potencializem o desenvolvimento de competências gerenciais. As ações de capacitação empreendidas pelas instituições, na maioria das vezes, abrangem competências técnicas e comportamentais: 
Acho que não se deve apenas dar as ferramentas para o chefe ser melhor, mas acompanhar seu aproveitamento, e ver as dificuldades da prática (...). Não apenas conhecimento técnico, abordar outros fatores, a exemplo do estresse [GVIII.20].

As competências comportamentais foram ressaltadas neste estudo pela compreensão de que a mudança comportamental é determinante no reconhecimento da capacitação e na redução do gap entre o desenvolvimento de competências gerenciais e de competências institucionais, o que demanda a necessidade de incorporar a lógica das competências a partir da análise da PNDP e do PCCTAE.

Constatou-se, ainda, que a autoeficácia e as competências gerenciais devem ser indissociáveis, uma vez que uma não se sustenta sem a outra, de modo que a crença numa capacidade irreal não alavanca os resultados esperados, tampouco possuir uma competência sem acreditar que a possui. Os servidores pesquisados que atuam em uma função gerencial acreditem que possuem as competências realmente adquiridas ao longo da sua trajetória profissional, independente da forma de aquisição.

A pesquisa sugere que a autoeficácia não está inserida no programa de capacitação da IFES de forma deliberada. O seu desenvolvimento acontece de modo emergente, a partir da persuasão social de alguns instrutores e da troca de experiências entre gestores, em cursos onde os instrutores favorecem esse processo. Ademais, ao mesmo tempo em que são percebidas oportunidades de melhoria desse programa e se discorre sobre abordagens que podem ser englobadas pela capacitação, ressalta-se um fator emergente em alguns discursos: o tempo. Os gestores indicaram que algumas vezes, abdicam de participar dessas ações, por causa da demanda de atividades e pelo senso de responsabilidade com a função.

Por fim, muitas variáveis precisam ser repensadas. Especialmente, compreende-se que a autoeficácia pode ser introduzida de forma deliberada na capacitação a fim de aperfeiçoar os seus resultados. As percepções obtidas nesta dimensão estão correlacionadas à teoria social cognitiva, que mostra a possibilidade de se desenvolver a autoeficácia em programas de capacitação. Ressalta-se que deter competências não e suficiente, é preciso acreditar que se é capaz de colocá-las em prática (BANDURA, 1988; NAVARRO, 2003).

\subsection{Os vínculos entre a capacitação e a autoeficácia de gerentes da IFE}

As pessoas com nível elevado de autoeficácia sentem menos estresse diante de situações que requerem mais esforço, bem como são mais motivadas e tendem a ser mais persistentes quanto ao alcance de seus objetivos (BANDURA, 1989). Sobre isso, percebeu-se que os gestores se vêem como persistentes: "Eu acho que é a persistência que move um gestor público" [GI.5]. Essa característica, sempre que citada, remete a aspectos culturais da administração pública, ressaltando que a persistência é imprescindível ao gestor que trabalha nesse contexto, já que os trâmites nessa esfera, bem como outras situações, refletem excesso de burocracia e resistência à mudança.

Uma das percepções reveladas a partir das categorias analisadas foi a importância das experiências vivenciadas pelos gestores, corroborando com Bandura $(1977 a, 1986)$ ao sugerir que as experiências de domínio constituem a fonte considerada como a de maior influência à autoeficácia, uma vez que se baseia em uma experiência de sucesso legítima. Assim, percebeu-se que os gestores se sentem seguros no exercício da função e uma análise de suas falas revela que essa segurança é advinda das experiências vividas não apenas na função atual, mas em outras experiências passadas:

“Hoje, sim. Logo no início, eu não tinha tanta segurança, não" [GV.2]. O gerente se sente (...) completamente seguro e preparado para assumir não só esse cargo, como também outro, na esfera administrativa [GIl.2]. 
Os resultados reforçam a importância do programa de capacitação potencializar a vivência de experiências no contexto da ação profissional, o locus onde acontecem as interações de trabalho dos gestores, para viabilizar a institucionalização de novos métodos de capacitação - tais como: treinamento no trabalho, estudos de casos práticos, mentoria, aprendizagem em ação - capazes de promover um processo reflexivo sobre a função gerencial e suas atividades. Isso pode, inclusive, otimizar os resultados da capacitação de modo a gerar mais aprendizagem e reduzir os custos de suas ações.

As relações sociais entre os gestores e sua equipe são determinantes para o compartiIhamento de ideias, a busca de soluções e a resolução de problemas, o que incide diretamente na autoeficácia desses gestores. Crenças de eficácia também determinam a quantidade de esforço usado para ultrapassar os obstáculos e o tempo despendido ou persistência para realização de uma tarefa. Baixos níveis de eficácia condizem com o abandono de situações profissionais enquanto que os níveis elevados indicam perseverança (BANDURA, 1986; MARTíNEZ; SALANOVA, 2006).

A observação vicária pôde ser entendida numa relação de reciprocidade, na percepção de alguns gestores entrevistados, pois a experiência adquirida e as capacitações obtidas resultaram no desenvolvimento de competências que os colocam como modelos a serem seguidos: Acho que as principais lideranças são aquelas que a gente sempre procura seguir, se espelhar! [GI.2]. Os gerentes pesquisados também se baseiam no desempenho de outros colegas gestores. Para Bandura (1986), os efeitos das experiências vicárias vão depender dos fatores percebidos como similares entre o observador e o modelo.

A persuasão verbal foi indicada como importante, embora não seja algo claramente vivenciado por alguns gestores. Alguns têm essa percepção a partir da confiança depositada por suas chefias imediatas: (...) minha preocupação era se o gestor com quem eu ía trabalhar me daria respaldo, $\mathrm{e}$ isso eu tive [GIV.3]. Bandura (1986) sugere que é mais difícil aumentar as crenças de autoeficácia, por meio da persuasão, do que reduzi-las. Essa é uma característica que carece de mais atenção. Embora não seja a fonte mais influente, ela tem o seu papel, em especial, associada a outras formas.

Um aspecto relevante envolve a capacidade dos gestores de lidar com as situações emocionais decorrentes da ação profissional. Deve-se crer que tudo o que foi exposto é verdadeiro. Todavia, perceberam-se alguns sinais de certo receio por parte dos entrevistados, de relatar estados que denunciassem fraqueza ou falta de habilidade em lidar com situações difíceis. Sobre isto, os sujeitos descreveram algumas alternativas úteis para amenizar tais estados, como: fazer ioga, hidroginástica e andar de bicicleta, entre outros. Estados fisiológicos confortáveis são mais prováveis de impulsionarem a pessoa a se sentir confiante em uma habilidade requerida ao desempenho de uma tarefa (BANDURA, 1986).

Há o entendimento de alguns gestores de que não deve existir diferença entre a mobilização das competências gerenciais, evidenciadas no setor público e no setor privado. Isso indica, de certo modo, uma crítica a traços da cultura do serviço público, que constituem, muitas vezes, entrave as mudanças necessárias à modernização das práticas de gestão pública. Todavia, isso deve ser algo institucionalizado e partilhado por todos os membros, e não apenas, representar a visão de alguns gestores.

Percebe-se que a cultura institucionalizada na IFES estudada tanto exerce influência nos gestores, como pode ser influenciada por eles, na medida em que se mostram perseverantes, servindo de modelo para suas equipes. As mudanças esperadas nas IFES requerem mudanças pessoais, que podem acontecer sob a consideração da cultura e da meritocracia, agentes indispensáveis a esse processo. Assim, a gestão por competência e a meritocracia podem promover o fortalecimento de uma cultura que caracterize uma instituição mais flexível e adaptável. 
As crenças de autoeficácia articulam as competências ao desempenho. 0 efeito das competências no desempenho não é direto, pois depende de crenças pessoais. É o esforço, a persistência e a perseverança que, em conjunto com as competências, influenciam o desempenho da pessoa. Há vezes em que um profissional que possui uma gama de conhecimentos e habilidades não consegue obter o resultado esperado enquanto outro com menor competência, mas com um nível elevado de autoeficácia, obtém um melhor desempenho (JAINA; TYSON, 2004).

Observa-se que os gestores têm a percepção de que conseguem mobilizar as competências desenvolvidas, por causa de diversos apontamentos, como: a permanência na função mesmo durante a mudança de gestão, a satisfação dos usuários sobre os serviços prestados na unidade, a visão da equipe, e a capacidade de resolução de problemas. Todavia, não fica claro que todas as competências adquiridas no decorrer da carreira, são mobilizadas em ação, quando necessário. Isso pode indicar que os gestores têm certa dificuldade de entendimento sobre o que é competência.

Fica evidente que o nível elevado de autoeficácia dos gestores estudados tem produzido resultados positivos no trabalho, ao passo em que eles se sentem mais seguros, conseguem lidar com situações difíceis e apontar diversas soluções aos problemas que surgem no exercício da função gerencial. Todavia, percebe-se que há pontos que podem ser mais explorados, inclusive em programas de capacitação, especialmente, formas de reduzir os estados fisiológicos e o incentivo a persuasão social, por parte de pessoas que tenham competência sobre o assunto, foco da ação a ser ministrada.

É preciso repensar a capacitação de modo a contemplar novas metodologias que proporcionem maior aproveitamento com relação à aprendizagem e sua difusão no contexto da ação profissional. A capacitação tal qual está delineada neste caso, se baseia no método tradicional de ensino, e embora os gestores tenham percebido que ela tem resultado em mudança de comportamento e fortalecimento da autoeficácia, eles mesmos, demonstraram a relevância das suas experiências para o desenvolvimento de competências e autoeficácia. Talvez isso demonstre que o resultado da aprendizagem vivencial tem implicado no aproveitamento das ações de aprendizagem.

Por outro lado, os resultados da pesquisa com os gerentes pesquisados revelaram que a cultura organizacional, a ausência de meritocracia, o contexto social e a demanda de trabalho, podem implicar na redução das crenças de autoeficácia, impactando negativamente a mobilização das competências no contexto profissional. Entre outros pontos, deve-se buscar instituir uma cultura flexível e adaptável que sirva de alicerce aos objetivos institucionais.

\section{CONCLUSÕES}

A análise dos discursos revelou percepções dos sujeitos acerca das implicações da capacitação com relação as suas crenças de autoeficácia e o desenvolvimento de competências dos gestores técnico-administrativos de uma IFES. Os resultados da pesquisa revelam a necessidade das IFES incluírem nos processos de capacitação, além da noção de competências, uma análise das crenças dos indivíduos acerca das suas capacidades, por meio da exploração do construto autoeficácia como um processo determinante no planejamento das ações de desenvolvimento gerencial.

Observou-se que a capacitação promoveu o desenvolvimento de competências, em especial, técnicas e comportamentais, e isso contribuiu para que os gestores a ampliarem as suas visões de mundo e visualizarem alternativas para a resolução de problemas, além de se sentirem mais seguros e melhorem o relacionamento com os servidores. De mesmo modo, os gestores revelaram que as experiências vividas foram relevantes ao desenvolvimento dessas competências e às suas crenças de autoeficácia. 
Sobre os vínculos entre o nível de autoeficácia e a capacitação dos gestores, conclui-se que os gestores pesquisados geram um impacto positivo em seu trabalho, em função de suas crenças de autoeficácia, uma vez que as experiências vividas contribuíram para a segurança na realização das atividades e também os ajudaram a lidar com as situações difíceis e os processos de solução de problemas.

A ação dos gerentes também é balizada pela experiência vicária, decorrente da percepção sobre o desempenho de outros colegas no ambiente de trabalho e das capacitações recebidas. As crenças de autoeficácia têm relação com as competências e o desempenho dos gerentes, mas também dependem das crenças pessoais, tais como o esforço, a persistência e a perseverança. Para potencializar as crenças de autoeficácia dos gerentes, os programas de capacitação deveriam incluir os estados fisiológicos, o incentivo a persuasão social, por meio da difusão de metodologias de aprendizagem orientadas para a ação e centradas na vivência de experiências.

A cultura organizacional exerce o papel de mediadora das crenças de autoeficácia e na organização estudada fatores como ausência de meritocracia, o contexto político e social e a demanda de trabalho, contribuem para diminuir a autoeficácia e a mobilização das competências na ação profissional.

Assim, para que a capacitação gere impacto na autoeficácia dos gestores é preciso institucionalizar uma cultura que favoreça a vivência de experiências de aprendizagem que levem os gerentes a transformarem as suas perspectivas de significado, impactando nos processos cognitivos e contribuindo para o desenvolvimento de suas experiências de domínio e vicárias, além da criação de um ambiente favorável ao feedback que pode contribuir para potencializar a persuasão verbal.

A valorização do servidor precisa ser algo comum a todos e incorporada na cultura organizacional. Os gestores precisam sentir a importância do seu papel para a Universidade. Os gestores de qualquer nível hierárquico também podem ter seus níveis de autoeficácia ampliados por meio do encorajamento de seus superiores, pares e subordinados, diante do reconhecimento das suas capacidades frente ao desempenho das suas atribuições. A crença do servidor público na sua capacidade de realizar ações e gerar resultados é fundamental para a gestão das IFES de modo geral, e não apenas para o processo de capacitação.

Uma reflexão relevante para este estudo é que a legislação relativa à capacitação nas IFES não vem sendo incorporada em sua totalidade, como revelaram Oliveira e Silva (2011). Desenvolver um programa de capacitação não é o suficiente, uma vez que vários aspectos não estão sendo desenvolvidos, a exemplo da gestão por competências (embora existam várias iniciativas em andamento em algumas IFES), da avaliação permanente dos resultados da capacitação, do desenvolvimento de programas de desenvolvimento gerencial, da designação de gestores capacitados para ocupar cargos de gestão, entre outros.

A introdução de perspectivas de aprendizagem experiencial e em ação nos programas de capacitação nas IFES pode contribuir na introdução de estratégias de aprendizagem que potencializem o desenvolvimento da autoeficácia dos gestores.

Espera-se que este estudo auxilie os agentes responsáveis pelas políticas públicas de gestão de pessoas no contexto das IFES no desenvolvimento de programas de capacitação que incorporem a autoeficácia como um construto que pode ser determinante para o desenvolvimento de competências gerenciais, mediados por processos de aprendizagem experienciais orientados para o contexto da ação profissional, pois tais processos estimulam o trabalho em equipe e a solução de problemas reais, a troca de experiências, a autonomia e a reflexão, de forma a promover o desenvolvimento da formação das pessoas.

Acredita-se que esse direcionamento pode contribuir para tornar os pressupostos e objetivos da PNDP mais próximos da realidade. Considerando que a autoeficácia é um construto pouco estudado no Brasil, em especial, no contexto da IFES, sugere-se a realização de novos estu- 
dos abordando alguns temas ligados à autoeficácia e à capacitação, tais como: a) desenvolvimento de uma escala de avaliação para análise das implicações da capacitação no desenvolvimento da autoeficácia; b) estudo comparativo entre gestores de várias IFES para avaliar a contribuição da capacitação no desenvolvimento de autoeficácia de gestores; c) analise da influência da cultura nos níveis de autoeficácia dos gestores de IFES; d) avaliação dos vínculos entre os estilos de liderança encontrados nas IFES e seus níveis de autoeficácia; e; e) realização de uma análise comparativa do nível de autoeficácia antes e após a participação dos gestores técnico-administrativos em curso de capacitação orientados para a gestão.

\section{REFERÊNCIAS}

ABBAD; Gardênia S.; BORGES-ANDRADE, Jairo E. Aprendizagem humana em organizações de trabalho. In: ZANELLI, José C.; BORGESANDRADE, Jairo E.; BASTOS, Antônio V.B. (Org.). Psicologia, organizações e trabalho no Brasil. Porto Alegre: Artmed, p. 237-275, 2004.

ARGYRIS, C.; SCHÖN. Organizational Learning II: Theory, Method, and Practice. Boston: Addison-Wesley, 1996.

AZZI, Roberta G.; POLYDORO, Soely. Autoeficácia proposta por Albert Bandura. In: AZZI, Roberta G.; POLYDORO, Soely (Org.). Autoeficácia em diferentes contextos. Campinas: Alínea, p. 9-23, 2006.

BACON, Kevin. Além da capacitação: desenvolvimento de líderes para o setor público. Revista do Serviço Público. Ano 50, n. 4, out./dez., 1999.

BANDURA, Albert. A social cognitive theory of personality. In PERVIN, Lawrence; JOHN, Oliver P. (Ed.), Handbook of personality. 2. ed. - New York: Guilford Publications. p. 154-196, 1999.

Human Agency in Social Cognitive Theory. American Psychologist, v. 44, n. 9, p. 1175-1358, 1989.

Organisational Applications of Social Cognitive Theory. Australian Journal of Management, v. 13, n. 2. December, 1988.

Social foundations of thought and action: A social cognitive theory. Englewood Cliffs, NJ: Prentice-Hall, Inc., 1986.
Self-efficacy mechanism in human agency. American Psychologist. v. 37, n. 2, 1982.

Self-efficacy: toward a unifying theory of behavioral change. Psycological Review, v. 84, n. 2, p.191-215, 1977a. Disponível em: $\quad<$ http://www.des.emory.edu/mfp/ Bandura1977PR.pdf>. Acesso em: 15 jun. 2011.

Social Learning Theory. New Jersey: Prentice Hall, 1977b.

BRANDÃO, Hugo P. Aprendizagem e competências nas organizações: uma revisão crítica de pesquisas empíricas. Revista Gestão. Org, v. 6, n. 3, p. 321-342, 2008.

BRASIL. Decreto no 5.825, de 29 de junho de 2006. Estabelece as diretrizes para elaboração do Plano de Desenvolvimento dos Integrantes do Plano de Carreira dos Cargos TécnicoAdministrativos em Educação, instituído pela Lei $n^{\circ} 11.091$, de 12 de janeiro de 2005. Brasília, DF, 30 jun. 2006. 2006b.

Decreto no 5.707, de 23 de fevereiro

de 2006. Institui a Política e as Diretrizes para o Desenvolvimento de Pessoal da administração pública federal direta, autárquica e fundacional, e regulamenta dispositivos da Lei ${ }^{\circ} 8.112$, de 11 de dezembro de 1990. Brasília, DF, 24 fev. 2006. 2006a.

Lei no 11.091, de 12 de janeiro de 2005. Dispõe sobre a estruturação do Plano de Carreira dos Cargos Técnico-Administrativos em Educação, no âmbito das Instituições Federais de Ensino vinculadas ao Ministério da 
Educação, e dá outras providências. Brasília, DF, 13 jan. 2005.

CARRIERI, Alexandre P., ET AL. Contribuições da análise do discurso para os estudos organizacionais. Revista Economia \& Gestão, v. 6, n. 12. 2006.

CAVALCANTE, Keliane O.; OLIVEIRA, Márcio M. Capacitação, para que te quero? Um Estudo sobre a Carreira dos Servidores Técnicoadministrativos e sua Contribuição para o Desenvolvimento de Competências Gerenciais. In: XXXV Encontro da ANPAD, 2011, Rio de Janeiro. Anais... Rio de Janeiro: ANPAD, 2011.

CHEETHAM, Graham; CHIVERS, Geoff. Professions, competence and informal learning. Edward Elgar: Cheltenham, 2005.

DAUDELIN, Marilyn W. Learning from experience through reflection. Organizational Dynamics, v. 24, n.3, p. 36-49, Winter 1996.

DUTRA, J. S. Competências: conceitos e instrumentos para a Gestão de Pessoas na empresa moderna. São Paulo: Atlas, 2004.

FARIAS, Pedro C.L.; GAETANI, Francisco. A política de recursos humanos e a profissionalização da administração pública no Brasil do século XXI : um balanço provisório. VII Congreso Internacional del CLAD sobre la Reforma del Estado y de la Administración Pública, Lisboa, Portugal, 2002. Anais... Lisboa: CLAD, 2002.

FLEURY, Maria T.L.; FLEURY, Afonso. Construindo o conceito de competência. RAC, Edição especial, p. 183-196, 2001.

GASKELL, George. Entrevistas individuais e grupais. In: BAUER, Martin W. \& GASKELL, George (org.). Pesquisa qualitativa com texto, imagem e som. Petrópolis: Vozes, 2008.

GODOY, Arilda S. Pesquisa qualitativa: tipos fundamentais. RAE, v. 35 , n. 3, p. 20-29, mai./ jun., 1995.
JAINA, Joe; TYSON, Shaun. Psychological similarity in work-based relationships and the development of self-efficacy beliefs. Human Relations. New York, v. 57, n. 3, p. 22, mar., 2004.

LE BOTERF, G. Desenvolvendo a competência dos profissionais. 3. ed. - Porto Alegre: Artmed, 2003.

MARTÍNEZ, Isabel. M. M.; SALANOVA, Marisa. Autoeficácia en el trabajo: el poder de creer que tú puedes. Estudios Financieros, v. 279, p. 175-202, 2006. Disponível em: <http:// www.wont.uji.es/wont/downloads/articulos/ nacionales/2006MARTINEZ06AN.pdf>. Acesso em: 20 fev. 2011.

MENESES, Pedro P.M.; ABBAD, Gardênia S. Locus de controle: validação de uma escala em situação de treinamento. Estudos de Psicologia, v. 9, n. 3, p. 441-450, 2004.

Construção e Validação de um Instrumento para Avaliar Auto-Eficácia em Situações de Treinamento, Desenvolvimento e Educação de Pessoas. Psicologia, Reflexão e Crítica, v. 23, n. 1, p. 121-130, 2010.

MERRIAM, Sharan B. Qualitative research: A guide to design and implementation. San

Francisco: John Wiley and Sons, 2009.

MERRIAM, S. B.; CAFFARELLA, R. S.; BAUMGARTNER, L.M. Learning in Adulthood: a compreesive guide. 3ed. San Francisco: John Wiley \& Sons, 2007.

MINTZBERG, Henry. MBA? Não, obrigado: uma visão crítica sobre a gestão e o desenvolvimento de Gerentes. Porto Alegre: Bookman, 2006.

NAVARRO, Leonor P. La autoeficacia en el contexto acadêmico, 2003. Disponível em: <http://www.des.emory.edu/mfp/prieto. PDF>. Acesso em: 15 jun. 2011.

NICOLAZZI, Emanuella M. S. Crenças de Servidores de uma Universidade Pública 
Federal em Relação à Gestão de Pessoas por Competências. Revista de Gestão Tecnológica, v. 3, n. 1, p. 20-30, jan./jun., 2013.

OLIVEIRA, Márcio M.; SILVA, Anielson B.; CAVALCANTE, Keliane O. O Sistema de Gestão de Pessoas por Competências na Universidade Federal de Goiás: "Sonho de uma Realidade" ou "Realidade de um Sonho"? In: XXXV Encontro da ANPAD, 2011, Rio de Janeiro. Anais... Rio de Janeiro: ANPAD, 2011.

PAJARES, Frank; OLAZ, Fabián. Teoria social cognitiva e auto-eficácia: Uma visão geral. In: BANDURA, Albert.; AZZI, Roberta. G.; POLYDORO, Soely. (Org.). Teoria Social Cognitiva: Conceitos básicos. Porto Alegre: Artmed, p. 97-114, 2008.

PANTOJA, Maria J., et al. Valores, suporte psicossocial e impacto do treinamento no trabalho. Estudos de Psicologia, v. 10, n. 2, p. 255-265, 2005.

PIRES, Alexandre K., et al. Gestão por competências em organizações de governo: mesa-redonda de pesquisa-ação. Brasília: ENAP, 2005.

SALAS, Eduardo; CANNON-BOWERS, Janis A. The science of training: a decade of progress. Annual Review of Psychology, v. 52, p. 471-499, 2001. Disponível em: <http://www-user.unibremen.de/ henning/Lehre/metaanalysen/ Sala_science_of_Training_ann_review.pdf $>$. Acesso em: 15 jun. 2011.

SILVA, Anielson B. Como os Gerentes Aprendem? São Paulo: Saraiva, 2009.

. O contexto social da aprendizagem de gerentes. Revista de Administração Mackenzie, v. 9, n. 6, p. 26-52, set./out., 2008.

A vivência de conflitos entre a prática gerencial e as relações em família. 2005. 221 folhas. Tese (Programa de Pós-Graduação em Engenharia de Produção) - Universidade Federal de Santa Catarina, Florianópolis, 2005.
SILVA, A. B.; GODOI, C.K.. O Processo de Aprendizagem Organizacional como balizador para o desenvolvimento de um modelo de competências para uma empresa do setor elétrico. Revista do Centro de Ciências Administrativas (UNIFOR), v. 12, p. 62-75, 2006.

TAMAYO, Natasha; ABBAD, Gardênia S. Autoconceito Profissional e Suporte à Transferência e Impacto do Treinamento no Trabalho. RAC, v. 10, n. 3, jul./set., 2006.

YIN, Robert K. Estudo de caso: planejamento e métodos. 2. ed. - Porto Alegre: Bookman, 2001. 